\title{
Representações visuais na modernidade líquida: o que os manequins falam de nós?
}

Visual representation of liquid modernity: what do the mannequins tell us?

\author{
Michely Calciolari Souza* \\ Universidade Estadual de Maringá \\ João Paulo Baliscei** \\ Universidade Estadual de Maringá \\ Teresa Kazuko Teruya*** \\ Universidade Estadual de Maringá
}

Resumo O fluxo de imagens, transformações tecnológicas e o culto ao corpo e à beleza são características que marcam a contemporaneidade. Fotografias, ilustrações e imagens da mídia difundem modelos com os quais as pessoas podem se identificar. Objetivou-se analisar como os sujeitos são representados pelos manequins de lojas. Para tanto, foi desenvolvida uma contagem de manequins em um shopping center da cidade de Maringá, Paraná. Foi constatado que os manequins representam, em sua maioria, as pessoas de cor ou raça branca. Verificou-se que o número de manequins de outras cores não corresponde ao número de brasileiros/as que se consideram pretos/as, pardos/as, amarelos/as ou indígenas. A partir disso, discutiu-se a importância da formação docente para os aspectos visuais da contemporaneidade.

PALAVRAS-ChAVE: Educação; Modernidade líquida; Pedagogias culturais.

\begin{abstract}
The flow of images, technological transformations and the body and beauty cult are same characteristics that spot the contemporaneity. Pictures, illustrations and images in the media diffuse models that represent us and in which we can identify ourselves. It was an objective to analyze how we are represented by the mannequins from the stores. For that, it was developed a count of mannequins in a mall inMaringácity, Paraná. It was realized that the mannequins represent, in their majority, the colored or white people. It was verified that the number of mannequins of different race colors do not correspond to the number of Brazilians that consider themselves black people, brown people , yellow people or red people. Based on this, it was discussed the importance of teacher's training to the visual aspects of the contemporaneity. KEYWORDS: Education; Liquid modernity; Cultural pedagogies.
\end{abstract}




\section{Introdução}

A contemporaneidade é marcada por situações atípicas em que o tempo e espaços são distintos daqueles vivenciados em outrora. As mídias oferecem informações em demasia, suas imagens exaltam a valorização do corpo e da aparência, além de estimularem a aquisição e descarte de produtos. O desenvolvimento tecnológico e a expansão da informática são alguns dos fatores que caracterizam a sociedade contemporânea, denominada por Bauman (2013a) por modernidade líquida.

O termo "líquido" faz menção à capacidade que as instituições e as pessoas contemporâneas têm de se ajustarem e de se adaptarem às situações distintas, o que faz com que suas formas, assim como a dos líquidos, sejam inconstantes. Além da modernidade líquida, o autor discorre sobre dois momentos que, embora diferentes entre si, possuem intersecções e pontos em comum: a pré-modernidade e a modernidade sólida ${ }^{1}$.

Essa explicação, ainda que sucinta, auxiliar-nos-á no entendimento de que os homens e mulheres da modernidade líquida são diferentes daqueles/as da pré-modernidade e da modernidade sólida. Bauman (2013a) avalia que, na pré-modernidade, os indivíduos se assemelhavam a guarda-caças. Os/as guarda-caças, como o próprio termo sugere, asseguram suas presas e poupam seus alimentos a fim de garantir sua subsistência. Assim também, os homens e mulheres pré-modernos acreditavam que a felicidade poderia ser alcançada por meio da estabilidade. Neste sentido, a felicidade consistia na segurança, rotina, controle e continuidade, isto é, em assegurar e preservar aquilo que já se tinha, a fim de garanti-lo.

Os homens e mulheres da modernidade sólida, por sua vez, são comparados/ as por Bauman (2013a) a jardineiros/as. Ao invés de proteger e salvaguardar suas caças, esses/as jardineiros/as preferem planejar e desenvolver estratégias para o progresso de seus jardins. Por isso, adubam o solo, plantam sementes, regam-nas, podam as plantas, protegem-nas de insetos e da exposição intensa ao sol, quando necessário, para que, por fim, possam desfrutar do resultado. Assim também eram os indivíduos da modernidade sólida: valorizavam a razão, o conhecimento científico, o planejamento a longo prazo e o progresso. Conforme o autor, tanto para os/as jardineiros/as quanto para os sujeitos da modernidade sólida, a felicidade e a satisfação são alcançadas no final do processo, quando desfrutam de sua organização e planejamento.

Bauman (2013a) destaca que na modernidade líquida, as pessoas se distanciam das características dos/as guarda-caças e dos/as jardineiros/as. Para representálas, o autor se utiliza da metáfora dos/as caçadores/as. Caçadores/as não almejam agir com cautela e planejamento para que, paulatinamente, possam acompanhar o processo e desfrutar dos resultados, como fazem os/as jardineiros/as, e nem pensam em proteger aquilo que já lhes pertence, como fazem os/as guarda-caças.

A caça é como uma droga: uma vez provada, transforma-se em hábito, necessidade interior e obsessão. A caçada de um coelho decerto se revelará uma decepção desagradável e aumentará o desejo de outro ensaio, pois a expectativa de uma caça exitosa será a experiência 
mais agradável (talvez a única?) de todo o evento. A caçada de um coelho põe fim a qualquer agitação, aumentando a expectativa. $\mathrm{O}$ único método para amenizar a frustração é planejar e iniciar imediatamente a próxima aventura. (BAUMAN, 2013a, p. 30).

Nesse exemplo, Bauman (2013a) sugere que, para o/a caçador/a, a felicidade não está na captura de sua presa (neste caso, o coelho), mas sim no próprio ato e desejo de caçar. Como consequência disso, quando o coelho é enfim capturado, ao invés de festejar, o/a caçador/a fica na expectativa da próxima caça.

Assim como os/as caçadores/as, os indivíduos da sociedade líquido-moderna valorizam a substituição e a descartabilidade em detrimento de tudo aquilo que é duradouro ou planejado a longo prazo. São características que nos instigam a pensar sobre a prática de consumo que, conforme aponta o autor, é uma das atividades mais frequentes na modernidade líquida.

Entendemos a captura do coelho como uma metáfora utilizada por Bauman (2013a) para se referir à aquisição de roupas, de brinquedos, de cosméticos, de objetos fetichizados, enfim, ao consumismo, já que, para muitos dos homens e mulheres da modernidade líquida, a satisfação está não necessariamente no desfrute do objeto comprado, mas, sim, no ato de comprar. Logo, diante de uma compra, é mais interessante pensarem em qual será sua próxima aquisição, do que tirarem proveito dos objetos adquiridos.

Bauman (2013a, p. 31) analisa que “[...] não é o fim da jornada que estimula o esforço, mas sua infinitude", isto é, para o/a caçador/a, a captura do coelho não representa o ápice da felicidade, mas sim a interrupção dela. Ora, de que nos adianta caçar se já temos o coelho? Da mesma forma, para os/as consumidores/as da modernidade líquida, ter a posse de todos os objetos e produtos que lhes são necessários representaria a interrupção da felicidade - ao menos que os produtos possam ser frequentemente trocados e substituídos.

Bauman (2013b) avalia que é isso que ocorre. Os consumidores/as líquidomodernos consideram que os objetos de desejo são fugazes, transitórios e passageiros. No mesmo instante em que determinado produto está no topo de sua popularidade, torna-se obsoleto e ultrapassado demais e, por isso, precisa ser substituído por outra novidade. Como conseqüência disso, a satisfação do sujeito se encontra na rotatividade e na permanente repetição de atos de descarte e aquisição de objetos ${ }^{2}$. Nesse sentido, mais do que em qualquer outro período, na modernidade líquida, as pessoas, e em especial as crianças e adolescentes, estão em intenso contato com os objetos que compõem as vitrines e prateleiras das lojas: roupas, sapatos, óculos, brinquedos, materiais escolares, chapéus, produtos eletrônicos, livros, eletrodomésticos, etc.

Hernández (2007) entende que, em uma cultura dominada por imagens, os objetos e representações visuais do cotidiano apontam modelos de vida e posições de sujeito com as quais devemos nos identificar e nos assemelhar. Denomina-se por cultura visual os artefatos culturais que, assim como aqueles que fizemos referência, atuam como discursos. 
Nessa reflexão, compartilhamos do entendimento que Wortmann (2005) tece acerca do que é discurso. Por exercerem efeitos sobre os indivíduos, os discursos oferecem características, imagens e representações como posições, nas quais podemos/ devemos nos enquadrar. Apresentam o que deve ser feito para que pertençamos a determinados grupos ou para que, ao menos, sejamos aceitos/as socialmente.

Tal situação pode ser evidenciada nos estudos que Kellner (2001) faz a respeito de anúncios publicitários de cigarro ${ }^{3}$. Os anúncios são organizados em dois grupos: aqueles direcionados especificamente para os homens e aqueles para as mulheres. Em ambos os grupos de anúncios, as composições visuais sugerem características desejáveis com as quais homens e mulheres devem se identificar. Nos anúncios destinados aos homens, destacam-se as características "consideradas" masculinas, como a força, o domínio de animais selvagens, agilidade, bravura e independência. Principalmente na década de 1950, para simbolizar tais características do "homem de verdade" (KELLNER, 2001), a marca de cigarros Marlboro usou insistentemente em suas campanhas a imagem do cowboy. Esse era representado usando roupas de couro e jeans, com a barba por fazer, com expressão séria, em contato com a natureza e com animais velozes e - é claro - fumando.

Os anúncios voltados para o público feminino, por sua vez, relacionam o ato de fumar com a esbelteza, charme, sensualidade e, principalmente, com o progresso das mulheres, uma vez que, até então, fumar era um hábito apenas dos homens. Nos anúncios analisados pelo autor, as mulheres são loiras, sorridentes, saudáveis, possuem corpos altos e magros e se exibem em posições sexualmente sugestivas. Frente a isso, Kellner (2001) destaca a necessidade de refletirmos sobre como nos relacionamos com os artefatos culturais, em especial, com aqueles que trabalham com a visualidade, como os filmes, os clipes e a publicidade.

$\mathrm{Na}$ educação escolar, é importante que também se ensine a analisar e a compreender os discursos midiáticos. Kellner (2012, p. 107) ressalta a necessidade de uma "pedagogia crítica das imagens", já que, conforme demonstrado, as mídias não só vendem os produtos, elas sinalizam também características sociais a serem imitadas.

Hernández (2007) chama atenção para o modo como olhamos e somos olhados/as pelas imagens da cultura visual. $\mathrm{O}$ autor sugere ainda que as práticas escolares devem incentivar experiências reflexivas críticas a respeito de como nos relacionamos com as representações visuais a nossa volta. $\mathrm{O}$ autor argumenta que não somente as imagens clássicas da História da $\mathrm{Arte}^{4}$ ou aquelas práticas consideradas eruditas, como um concerto de ópera ou uma apresentação de balé clássico, contribuem para a constituição de nossa subjetividade. Para além delas, a visualidade presente nas novelas, nos bailes funk, nas personagens de desenho animado, no cinema, nas tatuagens, nos passinhos de dança, nas bonecas, nos manequins das lojas e na cultura popular como um todo também são incorporadas nas atitudes, nos pensamentos e nas identidades de meninos e meninas em idade escolar. Hernández (2007, p. 31) destaca que essas “[...] representações visuais contribuem, assim como os espelhos, para a constituição de maneiras e modos de ver". Isso justifica a necessidade de refletirmos como esses artefatos culturais interpelam nossos pensamentos. 
Em nossa análise, essa relação se intensifica na questão das crianças e jovens por causa do contato exacerbado que esses/as têm com as imagens vinculadas às mídias eletrônicas, como o acesso a web e as Redes Sociais.

Baliscei e Teruya (2013) demonstram o modo como as imagens da cultura visual repercutem nas interpretações que os alunos e alunas fazem das produções da História da Arte. O autor e a autora apresentam interpretações de Guernica (1937) de Pablo Picasso (1881-1973) feitas por jovens do Ensino Fundamental. Nas produções dos alunos e alunas, as personagens de Guernica são transportadas para academias de musculação, bailes funk e para desenhos animados. Essas produções expressam as relações de trocas estabelecidas entre os indivíduos e os artefatos culturais que lhes são comuns.

Assim como Bauman (2010; 2013a; 2013b); Hernández (2007); Kellner (2001), Wortmann (2005) e Baliscei e Teruya (2013), enxergamos as representações visuais como pedagogias que educam, que valorizam o que deve ser usado, falado e pensado em detrimento daquilo que deve ser evitado, substituído e discriminado.

Esses estudos contribuem para que compreendamos os artefatos da cultura visual como discursos que estabelecem e difundem modelos do que é ser homem, mulher, criança, religioso/a, vulgar e, em especial em nossa reflexão, modelos de um corpo ideal. Frente a isso, questionamo-nos: Qual o ideal de corpo e de beleza masculina e feminina presentes nas representações visuais do cotidiano?

Para refletirmos a partir desse questionamento, desenvolvemos uma pesquisa quantitativa e qualitativa. É quantitativa pois preocupamo-nos em contar o número de manequins encontrados em um shopping center, na cidade de Maringá, Paraná. Escolhemos realizar essa contagem em um shopping center tendo em vista o aglomerado de lojas, a proximidade entre elas e a concentração de consumidores/as. Para a escolha do shopping center no qual a contagem foi feita, utilizamos como critério o tempo de sua existência. É qualitativa pois, a partir do que fora constatado no shopping center, buscamos organizar nossa análise subsidiando-a às reflexões de Bauman (2013a; 2013b); Hernández (2007); Kellner (2001); Sant'Anna (2012); Wortmann (2005). Sobre isso, trataremos no próximo item.

\section{Resultados e discussões}

Como anunciado anteriormente, neste momento faremos apresentação e análise dos dados coletados no shopping center. Antes disso, é interessante explanarmos que, para além dos critérios de escolha do shopping center, preocupamo-nos em eleger critérios para a seleção das lojas cujas vitrines seriam analisadas. Tendo em vista que nossa motivação inicial para a pesquisa adveio da relação que estabelecemos entre visualidade, ideal de beleza, propaganda e corpo, para delimitar nosso objeto de pesquisa, restringimo-nos a analisar apenas as vitrines de lojas que comercializam roupas. Desta forma, considerando o critério já mencionado, em nossa contagem foram contempladas 65 lojas, voltadas para o público infantil, para o masculino, para o feminino e, ainda, para uma combinação destes. 
Tendo selecionado nosso objeto de pesquisa, como primeiro procedimento, realizamos uma contagem dos manequins e representações visuais expostos nas vitrines das lojas. Consideramos como manequins tanto os/as bonecos/as que representavam todo o corpo humano quanto aqueles/as representativos/as apenas de partes, como busto, pernas e pés. Como representações visuais, consideramos as imagens fotográficas e ilustrativas que faziam menção ao corpo humano. Neste sentido, foram contempladas tanto as fotografias que compunham a vitrine, como também aquelas presentes nas embalagens e campanhas de marketing dos produtos. Ao todo, foram contabilizados 489 manequins e 108 representações visuais em cartazes e impressões.

Durante nossa primeira contagem, uma peculiaridade nos chamou atenção: o fato de que, aparentemente, o número de manequins brancos era maior que o número de manequins pretos. Diante disso, reorganizamos nossa contagem a fim de verificar se, quantitativamente, nossa hipótese procedia. Os dados podem ser observados na tabela seguinte:

Tabela 1: Relação entre as cores dos manequins e das representações em cartazes e impressões nas vitrines das lojas.

\begin{tabular}{l|l|l|l|l|l}
\hline \multirow{2}{*}{ Lojas } & \multicolumn{3}{|c|}{ Manequins } & \multicolumn{2}{l}{$\begin{array}{l}\text { Representações visuais em } \\
\text { cartazes e impressões }\end{array}$} \\
\cline { 2 - 6 } & Brancos & Pretos & Dourados & Brancos & Pretos \\
\hline Loja 1 & 22 & 0 & 0 & 4 & 0 \\
\hline Loja 2 & 16 & 0 & 0 & 0 & 0 \\
\hline Loja 3 & 6 & 0 & 0 & 2 & 0 \\
\hline Loja 4 & 7 & 0 & 0 & 0 & 0 \\
\hline Loja 5 & 7 & 0 & 0 & 0 & 0 \\
\hline Loja 6 & 8 & 0 & 0 & 0 & 0 \\
\hline Loja 7 & 3 & 2 & 0 & 0 & 0 \\
\hline Loja 8 & 4 & 0 & 0 & 0 & 0 \\
\hline Loja 9 & 5 & 0 & 0 & 0 & 0 \\
\hline Loja 10 & 3 & 0 & 0 & 1 & 0 \\
\hline Loja 11 & 3 & 0 & 0 & 0 & 0 \\
\hline Loja 12 & 10 & 3 & 0 & 0 & 0 \\
\hline Loja 13 & 15 & 1 & 0 & 0 & 0 \\
\hline Loja 14 & 8 & 0 & 0 & 0 & 0 \\
\hline Loja 15 & 8 & 0 & 0 & 4 & 0 \\
\hline Loja 16 & 17 & 0 & 0 & 15 & 2 \\
\hline Loja 17 & 7 & 0 & 0 & 1 & 0 \\
\hline Loja 18 & 3 & 2 & 0 & 0 & 0 \\
\hline Loja 19 & 9 & 0 & 0 & 0 & 0 \\
\hline Loja 20 & 9 & 0 & 0 & 2 & 0 \\
\hline Loja 21 & 6 & 0 & 0 & 0 & 0 \\
\hline & & & & & \\
\hline
\end{tabular}


Continuação Tabela 1

\begin{tabular}{|c|c|c|c|c|c|}
\hline Loja 22 & 2 & 0 & 0 & 7 & 0 \\
\hline Loja 23 & 16 & 2 & 0 & 0 & 0 \\
\hline Loja 24 & 9 & 0 & 0 & 1 & 0 \\
\hline Loja 25 & 6 & 0 & 0 & 4 & 0 \\
\hline Loja 26 & 5 & 0 & 0 & 0 & 0 \\
\hline Loja 27 & 4 & 0 & 0 & 0 & 0 \\
\hline Loja 28 & 1 & 0 & 0 & 0 & 0 \\
\hline Loja 29 & 7 & 3 & 0 & 0 & 0 \\
\hline Loja 30 & 7 & 0 & 0 & 5 & 0 \\
\hline Loja 31 & 8 & 0 & 0 & 5 & 0 \\
\hline Loja 32 & 4 & 0 & 0 & 0 & 0 \\
\hline Loja 33 & 5 & 1 & 0 & 1 & 0 \\
\hline Loja 34 & 5 & 0 & 0 & 1 & 0 \\
\hline Loja 35 & 5 & 0 & 0 & 1 & 0 \\
\hline Loja 36 & 6 & 0 & 0 & 14 & 1 \\
\hline Loja 37 & 0 & 6 & 0 & 0 & 0 \\
\hline Loja 38 & 6 & 0 & 0 & 0 & 0 \\
\hline Loja 39 & 7 & 0 & 0 & 0 & 0 \\
\hline Loja 40 & 3 & 0 & 0 & 0 & 0 \\
\hline Loja 41 & 7 & 0 & 0 & 0 & 0 \\
\hline Loja 42 & 3 & 0 & 0 & 0 & 0 \\
\hline Loja 43 & 3 & 0 & 0 & 1 & 0 \\
\hline Loja 44 & 3 & 0 & 0 & 0 & 0 \\
\hline Loja 45 & 0 & 0 & 5 & 0 & 0 \\
\hline Loja 46 & 0 & 18 & 0 & 12 & 0 \\
\hline Loja 47 & 5 & 0 & 0 & 0 & 0 \\
\hline Loja 48 & 10 & 0 & 0 & 17 & 0 \\
\hline Loja 49 & 8 & 0 & 0 & 0 & 0 \\
\hline Loja 50 & 18 & 0 & 0 & 4 & 0 \\
\hline Loja 51 & 6 & 0 & 0 & 0 & 0 \\
\hline Loja 52 & 9 & 0 & 0 & 0 & 0 \\
\hline Loja 53 & 11 & 0 & 0 & 0 & 0 \\
\hline Loja 54 & 8 & 0 & 0 & 0 & 0 \\
\hline Loja 55 & 1 & 0 & 0 & 0 & 0 \\
\hline Loja 56 & 9 & 0 & 0 & 0 & 0 \\
\hline Loja 57 & 4 & 0 & 0 & 0 & 0 \\
\hline Loja 58 & 2 & 0 & 0 & 0 & 0 \\
\hline
\end{tabular}


Continuação Tabela 1

\begin{tabular}{l|l|l|l|l|l}
\hline Loja 59 & 12 & 0 & 0 & 0 & 0 \\
\hline Loja 60 & 2 & 4 & 0 & 0 & 0 \\
\hline Loja 61 & 23 & 1 & 0 & 0 & 0 \\
\hline Loja 62 & 3 & 3 & 0 & 0 & 0 \\
\hline Loja 63 & 4 & 0 & 0 & 1 & 0 \\
\hline Loja 64 & 1 & 0 & 0 & 2 & 0 \\
\hline Loja 65 & 4 & 0 & 0 & 0 & 0 \\
\hline 65 & 438 & 46 & 5 & 105 & 3 \\
\hline
\end{tabular}

$\mathrm{Na}$ tabela 1, sintetizamos os dados das 65 lojas analisadas. Nessa tabela, constatamos que, de um total de 489 manequins, 438 são brancos, 46 são pretos e cinco são dourados. Isso representa quantitativamente $89,57 \%$ de manequins brancos, 9,4\% de manequins pretos e 1,02\% de manequins dourados, aproximadamente.

Das representações visuais, contamos um total de 108, sendo que 105 são de pessoas brancas e três são de pessoas pretas ${ }^{5}$, correspondendo, respectivamente a 97,22\% e 2,77\%, aproximadamente. Assim como nas análises de anúncios publicitários de cigarros, realizadas por Kellner (2001), constatamos que as lojas do shopping center também expressam os modelos de identificação e posições de sujeitos com as quais devemos nos assemelhar. Dizemos isso pois, em nossa contagem de manequins e imagens das vitrines, os dados apontam que as representações de pessoas brancas de padrão europeu predominam em comparação com as demais cores.

Diante dos dados coletados, interessamo-nos por compará-los ao número de pessoas brancas e pretas em nível nacional e estadual. Para isso, recorremos às pesquisas realizadas pelo Instituto Brasileiro de Geografia e Estatística ${ }^{6}$ (IBGE) no ano de 2010. Em um total de 190.755.799 brasileiros/as entrevistados/as, 91.051.646 se declararam da cor/ou raça branca, o que corresponde à 47,73\%, aproximadamente. Outros/as 99.400.545, que correspondem à aproximadamente 52,10\%, se declararam da cor/ou raça preta, parda, amarela ou indígena ${ }^{7}$.

No que diz respeito à cor/ou raça dos/as paranaenses ${ }^{8}$, de um total de 10.444.526 entrevistados/as, 7.344.122 se declararam como brancos/as, 3.100.328 se declararam como pretos/as, pardos/as, amarelos/as ou indígenas e 76 não declararam sua cor/ou raça. Esses dados correspondem, respectivamente, a 70,31\%, 29,68\% e 0,01\% dos/as participantes, aproximadamente.

Ocorre que, quando cruzamos os dados obtidos em nossa contagem com os dados das pesquisas do IBGE (2010), percebemos uma significativa discrepância. (conforme Tabela 2). Ao inserirmos a quantidade de manequins e representações visuais em porcentagem, verificamos que o número de manequins e de representações visuais que são diferentes do padrão branco não corresponde, nem aproximadamente, ao número de pessoas que não se declaram da cor/ou raça branca. 
Tabela 2: Relação de cores/ou raças entre manequins, representações visuais, população brasileira e paranaense.

\begin{tabular}{l|l|l|l}
\hline \multicolumn{2}{l|}{} & Cor ou raça branca & $\begin{array}{l}\text { Outras Cores ou } \\
\text { raças }\end{array}$ \\
\hline \multirow{2}{*}{ Pesquisas nossas } & Manequins (\%) & $89,57 \%$ & $10,42 \%$ \\
\cline { 2 - 4 } & $\begin{array}{l}\text { Representações } \\
\text { Visuais (\%) }\end{array}$ & $97,22 \%$ & $2,77 \%$ \\
\hline $\begin{array}{l}\text { Pesquisas do IBGE } \\
(2010)\end{array}$ & Brasileiros/as (\%) & $47,73 \%$ & $52,10 \%$ \\
\cline { 2 - 4 } & Paranaenses (\%) & $70,31 \%$ & $29,68 \%$ \\
\hline
\end{tabular}

A divulgação de modelos de beleza oferece estereótipos que marcam um ideal apresentado como se fosse pertencente à maioria das pessoas: cabelos longos e lisos, olhos claros e maquiados, corpo magro, esguio e branco. Mas, conforme demonstrado, a raça/cor branca representa uma parte dos indivíduos. Mesmo que essas características correspondam aos atributos físicos de uma minoria - branca -, ainda assim são apresentadas como a norma a ser seguida por todos/as.

Morin (2011) observa que a cultura de massa difunde modelos que suscitam desejos de imitações. Identificamo-nos com os penteados, cílios, bronzeado, maquilagens e com as vestimentas das vedetes e celebridades que aparecem com frequência nas novelas, no cinema e nas páginas das revistas. Seja por causa da identificação que temos com esses heróis e heroínas da cultura de massa ou por causa de nossa necessidade de "estarmos na moda", muitas vezes reproduzimos os elementos de sua estética. Acontece que, assim como avisa o autor, a necessidade e vontade de imitação podem se tornar compulsórias, insatisfeitas e insaciáveis, tendo em vista, primeiramente, que muitos dos modelos de estética são inatingíveis. Em suas palavras "[...] a projeção pode ser a tal ponto fascinante que ocasiona uma espécie de conversão hipnótica da vida, que se sonambuliza, e cuja seiva toda se escoa no consumo imaginário"(MORIN, 2011, p. 77).

Se isso não bastasse, na modernidade líquida, as tendências de moda e de beleza são tão líquidas quanto os indivíduos: mudam seu formato e sua estrutura o tempo todo. Assim, aqueles/as que querem "estar na moda" tem suas preocupações duplicadas: têm que estar atentos/as com o que é novo (para sua aquisição), assim como com o que é ultrapassado (para seu descarte).

Hoje, os símbolos de "estar na vanguarda" devem ser adquiridos depressa, enquanto os de ontem, da mesma forma, devem ser confinados à pilha de refugos. A regra de ficar de olho naquilo "que já saiu de moda" deve ser observada tão conscienciosamente quanto a obrigação de permanecer no topo do que é (neste momento) novo e atual. $\mathrm{O}$ estilo de vida declarado pelos[/as] que dele desfrutam ou a ele aspiram [...] também é definido pela preeminência dos símbolos das últimas tendências e pela ausência daqueles que não estão mais na moda. (BAUMAN, 2013a, p. 25). 
Nesta lógica, as roupas, acessórios, penteados, enfim, os guarda-roupas devem se renovar conforme as tendências se modificam. No que diz respeito à beleza e à moda, o autor compara a identidade dos indivíduos da sociedade líquido-moderna com um camaleão, pois estão o tempo todo se transformando, adaptando-se ao cenário no qual estão inseridos. Como consequência disso, qualquer tratamento para se atingir (ou ao menos se aproximar) dos padrões oferecidos pelos artefatos culturais, dentre esses os manequins e as representações visuais, são compreendidos e aceitos socialmente, como aponta Sant'Anna (2012):

Parece que o corpo se tornou o centro de uma espécie de combate permanente, no qual aliados/as e inimigos/as pouco se distinguem. Quem não for à luta, quem desertar desse campo fisiológico, expressa fraqueza, mostra a pior das covardias, merece, portanto, desprezo [...]. Por isso, tal como em várias batalhas, as formas de luta importam menos do que a coragem para empreendê-la. Não por acaso, vale tudo: cirurgias, preenchimento facial, rejuvenescimento por laser, bronzeamento, branqueamento, mas também adesão a vários tipos de moda, ou antimoda [...]. (SANT'ANNA, 2012, p. 124).

Existe uma determinação normativa que induz o indivíduo a buscar o corpo e a aparência ideais que, conforme o discurso da publicidade, podem ser reais e acessíveis, basta buscarmos os mecanismos adequados para isso: cirurgias estéticas, dietas, treinos em academia, tratamentos artificiais, moda e cosméticos. Tais instrumentos são aperfeiçoados e substituídos com rapidez pelo mercado de consumo. Essa questão se intensifica se levarmos em conta que, conforme Bauman (2013a), na modernidade líquida, tudo e todos/as são passíveis de descarte e adaptação.

Além dos dados expostos, avaliamos outros itens que dizem respeito à visualidade dos manequins pretos. Em duas lojas, por exemplo, quando comparamos o rosto dos manequins brancos com o dos manequins pretos, analisamos que as características e traços são semelhantes: rosto magro, lábios finos, sendo que o lábio superior é equivalente ao inferior, nariz levemente arrebitado e queixo e maxilar bem desenhados (Figura 1). Diante disso, nossa hipótese é a de que os dois manequins, branco e preto, foram feitos a partir do mesmo molde.
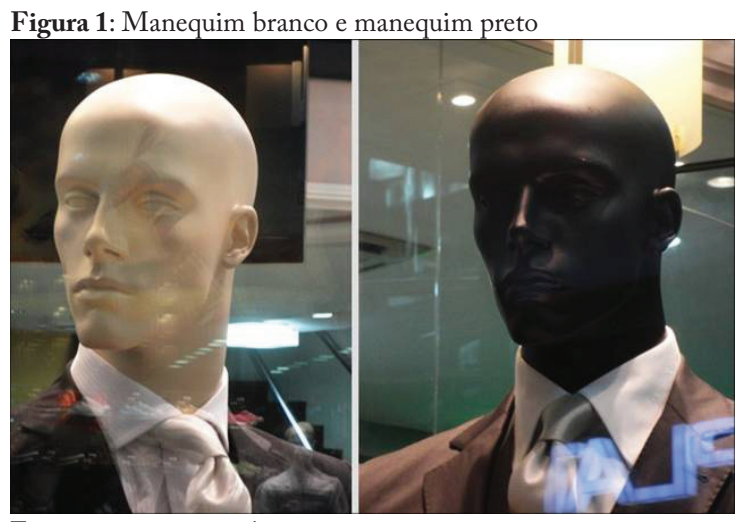

Fonte: registro pessoal, 2014. 
Em nossa interpretação, ainda que considere a cor/raça preta, em sua visualidade, o manequim não representa as características físicas reais dos homens pretos. Ao contrário disso, parecem mais reproduzir os traços característicos dos brancos, nos manequins pretos.

A Figura 2 ilustra três manequins. Mesmo que não sejam pintados da cor preta, ainda assim, em nossa análise, são representativos da cor/raça preta. Além de se diferenciarem da cor dos demais manequins, em sua maioria branca, apresentam características comuns aos homens e mulheres da cor/raça referida: pele bronzeada, lábios carnudos, nariz saliente e mais arredondado, olhos castanhos e cabelos crespos.

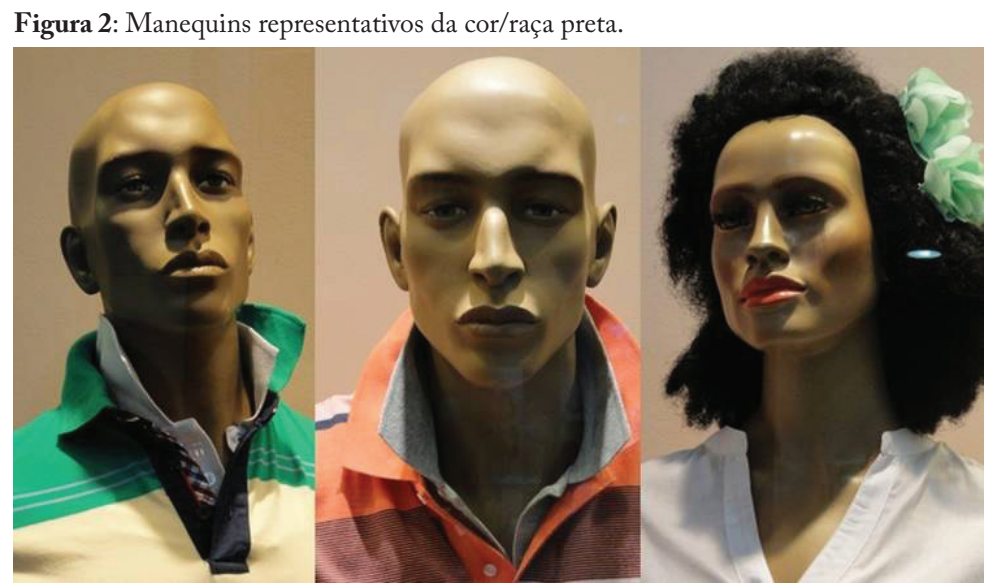

Fonte: registro pessoal, 2014.

Interessante que, quando comparamos esses três manequins com os manequins brancos que compunham a vitrine dessa mesma loja, percebemos que não compartilhavam das mesmas características e traços, isto é, que não foram produzidos a partir do mesmo molde.

Ressaltamos que, sob um olhar superficial, essas questões passariam como despercebidas, uma vez que já frequentamos o referido shopping center por diversas vezes e que foi somente no desenvolvimento da pesquisa que nos atentamos para essa análise crítica. Rogoff (1998, apud HERNADÉZ, 2007) faz a descrição do "olho curioso". Denomina por "olho curioso" aquele que busca enxergar para além do óbvio, do que está aparente. O "olho curioso" permanece inconformado, investigativo e inquieto, tentando enxergar aquilo que não é imediatamente identificável.

A partir disso, destacamos a necessidade de intervenções pedagógicas que considerem os artefatos visuais, tais como as representações e os manequins, como pedagogias culturais, partindo do fato de que oferecem modelos que educam. Além disso, esses artefatos suscitam nossa reflexão para observar o modo como as crianças e jovens se relacionam com a visualidade, na modernidade líquida, e desenvolver estratégias de intervenção pedagógica para que esses/as passem a "olhar curiosamente" as imagens a sua volta. 
Nunes (2010) aponta que as salas de aula são cenários pertinentes para propostas de discussões e análises dos elementos da cultura visual, uma vez que as imagens também "invadem" $\mathrm{o}$ espaço escolar: as mochilas, cadernos, estojos e demais materiais escolares dos meninos e meninas carregam estampas, desenhos e referências imagéticas que os/as produzem constantemente.

As práticas escolares ainda se mostram defasadas, pois procuram constantemente enquadrar seus educandos [e educandas] em uma única linha de formação, sem articular a sala de aula às problemáticas que estão "em alta" em todos os outros campos sociais. Entre essas, encontram-se as artes visuais da contemporaneidade, que através da Cultura Visual, buscam desestabilizar nossos sentidos e provocar diferentes leituras e interpretações. (NUNES, 2010, p. 14-15, grifos nossos).

Entendemos por "problemáticas que estão 'em alta” elementos como beleza, corpo "ideal", futebol, saúde, sexualidade, relacionamento, acesso a web e outros assuntos recorrentes nas mídias e que, por isso, são bastante próximos e comentados pelos meninos e meninas em idade escolar. Essas problemáticas, por vezes, são representadas visualmente nos filmes de cinema, nas novelas, nos outdoors e, como demonstramos, nos manequins e representações fotográficas. Cunha (2012, p. 101) diz que "muito mais do que elaborar os imaginários infantis, as imagens [da cultura visual] se colam às crianças como se fossem suas 'verdadeiras' peles".

Apesar dessa compreensão, conforme as autoras, as intervenções pedagógicas que os professores e professoras desenvolvem para tratar da visualidade são pouco eficientes, pois não correspondem a intensidade e a qualidade do contato que os/as jovens e as crianças têm com as tecnologias, com a cultura popular e com as mídias visuais. Além disso, muitas escolas, ainda hoje, trabalham apenas com as manifestações culturais/artísticas consideradas como eruditas, desconsiderando, assim, as demais culturas que não se enquadram neste modelo ideal, dentre elas a cultura visual (NUNES, 2010). Cunha (2012, p. 13) argumenta que, com frequência os modelos oferecidos pelos artefatos da cultura visual "[...] vão sendo naturalizados e aceitos rapidamente [pelos alunos e alunas] e a escola - e nós professoras [e professores] - fechamos nossos olhos para esses universos simbólicos/ estéticos".

Assim como as autoras, demonstramos nossa preocupação com o modo como as crianças e jovens veem e são vistos pelos artefatos da cultura visual e reforçamos a importância em se desenvolver estudos visuais críticos durante as propostas escolares. Para que isso ocorra, entendemos ser fundamental que professores e professoras enxerguem o potencial pedagógico das imagens do cotidiano e que problematizem os conteúdos e representações difundidos pela visualidade.

\section{Considerações finais}

Visualidade e descartabilidade são elementos valorizados por homens e mulheres da modernidade líquida. Os meios de comunicação e as imagens presentes nos anúncios publicitários, nas campanhas de marketing e nas vitrines das lojas oferecem modelos de comportamento e beleza do corpo. Pensando nisso, analisamos o modo 
como somos representados pelos manequins de um shopping center de Maringá, Paraná. Dentre os elementos observados, destacamos a cor.

Os dados analisados, assim como as reflexões que fizemos, asseveram o contraste entre as representações dos/as brancos/as e as representações dos/as não brancos/as. Neste sentido, frente aos estudos apontados e aos dados apresentados por nós e pelas pesquisas do IBGE (2010), podemos refletir que os/as brancos/as correspondem à normatividade, à hegemonia. A cor ou raça branca está presente na maioria dos manequins e das representações visuais. Enquanto isso, ainda que ocupem um percentual significativo na sociedade brasileira, como demonstra os dados do IBGE (2010), as pessoas que se declararam de outras cores/ou raças são pouco representadas pelos manequins e figuras das vitrines.

Entendemos que, para repensar a visualidade e suas implicações para o corpo e a subjetividade dos indivíduos, é importante a reflexão docente sobre os modos como olhamos e somos olhados pelos artefatos culturais, dentre eles, os manequins. Essa reflexão é necessária na formação de professores/as para incorporar na prática pedagógica a problematização da visualidade do cotidiano. Assim, os/as estudantes terão condições de questionar as imagens a sua volta e de olhar para além daquilo que é percebido de imediato.

\section{Referências}

BALISCEI, J. P.; TERUYA, T. K. Leitura e releitura de imagens: possibilidades de desenvolvimento de alfabetização visual crítica. In: Anais do XI Congresso Nacional de Educação EDUCERE, 2013, Curitiba, Pontifícia Universidade Católica, 2013, p. 18068-18079.

BAUMAN, Z. Capitalismo parasitário: e outros temas contemporâneos. Tradução Eliana Aguiar. Rio de Janeiro: Zahar, 2010.

BAUMAN, Z. A cultura no mundo líquido moderno. Tradução de Carlos Alberto Medeiros. - Rio de Janeiro: Zahar, 2013a.

BAUMAN, Z. Sobre educação e juventude: conversas com Ricardo Mazzeo. Tradução Carlos Alberto Medeiros. Rio de Janeiro: Zahar, 2013b.

CUNHA, S. R. V. da. Questionamentos de uma professora de arte sobre o ensino de arte na contemporaneidade. In: MARTINS, R.; TOURINHO, I. (Orgs.). Cultura das imagens: desafios para a arte e para a educação. Santa Maria: Ed. da UFSM, 2012. p. 99-123.

HERNÁNDEZ, F.; Catadores da cultura visual: transformando fragmentos em nova narrativa educacional. Tradução Ana Duarte. Porto Alegre: Mediação, 2007.

IBGE, Dados do Censo 2010 publicados no Diário Oficial da União do dia 04/11/2010. Brasília: 2010. Disponível em: <http://censo2010.ibge.gov.br/resultados>. Acesso em: 27 maio 2015.

KELLNER, D. A cultura da mídia.Tradução Ivone Castilho Benedetti. Bauru: EDUSC, 2001.

. Lendo imagens criticamente: em direção a uma pedagogia pós-moderna. In: SILVA, T. T. (Org.). Alienígenas na sala de aula. Petrópolis: Vozes, 2012. p. 101-127.

MORIN, E. Cultura de massa no século XX: espírito do tempo I: neurose. Trad. Maura Ribeiro Sardinha. 10. ed. Rio de Janeiro: Forense Universitária, 2011.

NUNES, L. B. As imagens que invadem as salas de aula: reflexões sobre cultura visual. Aparecida: Ideias \& Letras, 2010. 
SANT'ANNA, D. B. Sempre bela. In.: PINSKY, C. B.; PEDRO, J. M. (Org.). Nova história das mulheres. São Paulo: Contexto, 2012.p. 105-125.

WORTMANN, M. L. C. Dos riscos e dos ganhos de transitar nas fronteiras dos saberes. In: COSTA, M. V.; BUJES, M. I. E. Caminhos investigativos III: riscos e possibilidades de pesquisar nas fronteiras. Rio de Janeiro: DP\&A, 2005. p. 45-67.

\section{Notas}

${ }^{1} \mathrm{O}$ termo "sólido" caracteriza a estrutura rígida e fixa da sociedade, na qual os indivíduos valorizam elementos duradouros, como compromisso e fidelidade.

2 Além disso, como aponta Bauman (2013a; 2013b), essas características do consumo na modernidade líquida podem ser percebidas em outros aspectos da sociedade, tais como nos relacionamentos familiares, na construção de imóveis, na identidade, na arte, nas concepções a respeito do corpo e na educação.

${ }^{3}$ Kellner (2001) analisa cartazes publicitários da Marlboro e Virginia Slims.

${ }^{4}$ Aqui, utilizamos os termos “imagens clássicas da História da Arte”, para nos referirmos à composições de artistas consagrados e conhecidos como Pablo Picasso (1881-1973) e Edward Munch (1863-1944).

${ }^{5}$ Utilizamos a palavra "preto/a" para nos referirmos a cor/ou raça, conforme o faz as pesquisas do IBGE (2010).

${ }^{6}$ Disponível em: <ftp://ftp.ibge.gov.br/Censos/Censo_Demografico_2010/Resultados_do_Universo/tabelas_pdf/tab3.pdf $>$. Acesso em: 24 nov. 2013.

${ }^{7}$ Ainda segundo a mesma fonte, dos/as entrevistados/as, 6.608 não declararam sua cor/ou raça. (IBGE, 2010).

${ }^{8}$ Disponível em: <http://www.ibge.gov.br/estadosat/temas.php?sigla=pr\&tema=resultuniverso_censo2010>. Acesso em: 28 nov. 2013.

${ }^{9}$ Utilizamos o termo "invadem" para fazer referência ao título "As imagens que invadem as salas de aula" (NUNES, 2010).

* Mestranda em Educação pela Universidade Estadual de Maringá, Maringá, Paraná, Brasil.

** Professor mestre da Universidade Estadual de Maringá, Maringá, Paraná, Brasil.

**** Professora doutora da Universidade Estadual de Maringá, Maringá, Paraná, Brasil.

\section{Correspondência}

Michely Calciolari de Souza - Universidade Estadual de Maringá. Av. Colombo, Zona 07, CEP: 87030900 - Maringa, Paraná, Brasil.

E-mail:michely_calciolari@hotmail.com - vjbaliste@gmail.com - tkteruya@gmail.com

Recebido em 02 de junho de 2014

Aprovado em 28 de julho de 2014 